\title{
Association of HLA-G 14-base pair insertion/deletion polymorphism with breast cancer in Saudi Arabia
}

\author{
S.Y. Al Omar and L. Mansour \\ Zoology Department, College of Science, King Saud University, Saudi \\ Arabia
}

Corresponding author: L. Mansour

E-mail: lamjed.mansour@gmail.com

Genet. Mol. Res. 18 (2): gmr18263

Received November 14, 2018

Accepted April 08, 2019

Published April 30, 2019

DOI http://dx.doi.org/10.4238/gmr18263

\begin{abstract}
Human leukocyte antigen-G (HLA-G) has been associated with various immune diseases, including malignancies. The 14-base pair (bp) insertion/deletion (indel) polymorphism (rs16375) in exon 8 of the $3^{\prime}$ untranslated region ( $3^{\prime}$ UTR) of the HLA-G gene has been reported to influence HLA-G protein expression. We investigated the relationship between the 14-bp indel polymorphism and the occurrence of breast cancer in a Saudi population. The HLA-G 14-bp polymorphism was typed by PCR in 52 patients with breast cancer and 62 healthy control Saudi women. There was a highly significant association between the occurrence of breast cancer and the del allele $(\mathrm{OR}=3.75 ; \mathrm{P}<0.001)$ and the del/del genotype $(\mathrm{OR}=4.96 ; \mathrm{P}<0.001)$. Conversely, the 14-bp ins allele and ins/ins genotype exhibited protective effects against breast cancer ( $\mathrm{P}<0.00001)$. Remarkably, the genotype 14-bp ins/ins was missing among all patients. This is the first report showing a strong association between HLA-G 14-bp polymorphism and breast cancer in the Saudi population. The results are in agreement with previous reports showing similar association of HLA-G and breast cancer in other populations.
\end{abstract}

Key words: HLA-G; Genetic polymorphism; Breast cancer; Saudi Arabia 


\section{INTRODUCTION}

The human leukocyte antigen-G $(H L A-G)$ gene is a part of the non-classical HLA class Ib family, positioned at chromosome $6 \mathrm{p} 21.2-21.3$ within the human complex antigen gene family between the HLA-A and HLA-F genes ( Geraghty et al., 1987; Koller et al., 1989; Carosella et al., 1999; Dausset and Carosella, 1999; Jun and Katsumi, 2009;) . The $H L A-G$ gene consists of 7 introns and 8 exons coding the heavy chain of the molecule. Exon 1 encodes the peptide signal, while exons 2,3 , and 4 encode the extracellular domains $\alpha 1$, $\alpha 2$, and $\alpha 3$, of the heavy chain, respectively (Jun and Katsumi, 2009). Exons 5 and 6 encode the transmembrane and cytoplasmic domains. Exon 7 is never present in the mature mRNA because of a stop codon in exon 6; exon 8 is also not translated. The $3^{\prime}$-untranslated region (UTR) of the HLA-G gene contains several regulatory elements including AU-rich motifs and a poly-A signal to influence mRNA stability, turnover, mobility, and splicing pattern (Donadi et al., 2011). The HLA-G gene promoter sequence is slightly different from that of other class I genes, and a few alternative regulatory elements are present to regulate HLA-G gene transcription (Gobin and van den Elsen, 1999). Seven different isoforms have been identified, encoded through alternative splicing of the primary transcripts. Four of the isoforms are membrane-bound (HLA-G1, -G2,-G3, and -G4) and lack intron-4, while three are soluble (HLA-G5, -G6, and -G7) and contain intron-4 (Rebmann et al., 2007). The gene coding the HLA-G $\alpha$ chain is characterized by a low level of allelic polymorphism compared to HLA class I genes. Approximately 50 polymorphic sites have been mapped either in non-coding or coding regions (IMGT HLA database, December 2013). The HLA$\mathrm{G}$ molecule was reported for its tolerogenic function mainly in the maternal-fetal interface, helping to protect the fetus from destruction by the mother's immune defense system (Kovats et al., 1990; Menter and Tzankov, 2018; Galaviz-Hernandez et al., 2019). Considering the tolerogenic properties of the HLA-G molecule, many studies have detected an association between the aberrant expression of HLA-G and the occurrence of several types of malignancies such as colorectal cancer, esophageal cancer, uterine cervical cancer, ovarian carcinoma, hepatocellular carcinoma, carcinoma of bladder, and breast cancer (Rouas-Freiss et al., 2005a; Zidi and Ben Amor, 2011; Kim et al., 2013; Rolfsen et al., 2014; Rutten et al., 2014; Zhang and Tao Wang, 2014; Zidi et al., 2016; Zambra et al., 2016; de Almeida et al., 2018; Lin and Yan, 2018) as well as several other diseases such as infections, autoimmunity, and abortion (Donadi et al., 2011; Vargas et al., 2011; Garcia et al., 2013; Dias et al., 2015; Sabbagh et al., 2018;). Different polymorphisms located in coding and noncoding regions of the gene were reported to affect the biological activity of HLA-G. Polymorphism in the promoter or 3'-UTR influence HLA-G levels. One of the most studied polymorphism is the 14-base pair (bp) (5'- ATTTGTTCATGCCT-3') insertion/deletion ( $\mathrm{in} / \mathrm{del}$ ) of the $3^{\prime}$ UTR at position 3741 in exon 8 , which regulates expression of the HLA-G molecule (Carosella et al., 2008b). Breast cancer is considered the most common neoplasm affecting women and the most frequent cause of cancer-related mortality worldwide (Anderson et al., 2015; Hortobagyi et al., 2005). According to GLOBOCAN 2012, the estimated number of newly diagnosed cases was 1.7 million, accounting for 522,000 cancer-related deaths in 2012 (Torre et al., 2015). Since the 2008 estimates, the incidence of breast cancer has increased by more than $20 \%$, while mortality has increased by $14 \%$. In Saudi Arabia, according to the National Cancer Registry, the incidence of breast cancer (BC) is 127.8 per 100,000 women and the mortality rate was 
reported to be 25.5 per 100,000 between 2000 and 2004. Although the global burden of BC has increased, early detection to improve outcome and survival may reduce mortality (Gibbons et al., 2016). Therefore, identifying appropriate tumor markers for early detection and monitoring is necessary. Currently, no markers are available for early diagnosis of BC. In the current study, we evaluated the association between the 14-bp insertion/deletion polymorphism of the $H L A-G$ gene and $\mathrm{BC}$ in a Saudi population living in Riyadh city.

\section{MATERIAL AND METHODS}

\section{Study subjects}

A total of 52 patients with breast cancer who agreed to participate in our study were randomly selected. The patients (mean age $41 \pm 11$ ) diagnosed at the King Khaled Hospital University (KKHU) were confirmed as having BC based on the pathological features of tissue specimens. Patient data including age, tumor grade, and clinical stage were also recorded (Table 1). Sixty-two healthy, unrelated, female volunteers (mean age $35 \pm 8$ years) were also enrolled as controls from among individuals who visited the KKHU for physical checkups and who had no clinical evidence of $\mathrm{BC}$ or any other chronic disease. Both patients and controls provided informed consent to participate in the study. The study protocol was approved by the Institutional Review Board of the Ethics Committee at King Khalid University Hospital in Riyadh, KSA.

Table 1. Demographic and main clinical data of breast cancer patients and controls used for genotyping.

\begin{tabular}{|c|c|c|c|}
\hline Characteristic & & Patients & Controls () \\
\hline Age (year) & & $41 \pm 11$ & $38 \pm 8$ \\
\hline Estrogen & ER+ & 94.2 & - \\
\hline (ER)/Progesterone (PR) & ER- & 5.8 & \\
\hline \multirow[t]{3}{*}{ receptors $(\%)$} & $\mathrm{PR}+$ & 96.2 & - \\
\hline & PR- & 3.8 & \\
\hline & Tamoxifen (20mg/day) & Yes $\quad 100$ & - \\
\hline Therapy (\%) & & No & - \\
\hline \multirow{4}{*}{ Stage $(\%)$} & & 11.5 & - \\
\hline & & 46.2 & - \\
\hline & & 34.6 & \\
\hline & & 7.7 & \\
\hline
\end{tabular}

\section{Genomic DNA extraction and 14-bp polymorphism genotyping}

Genomic DNA was extracted from ethylene diamine tetra acetic acid (EDTA)peripheral blood samples by using the Puregene purification kit (Qiagen, Hilden, Germany) following the manufacturer's instructions. The HLA-G 14-bp polymorphism within the 3'UTR of exon 8 was amplified by polymerase chain reaction (PCR) using the primers GE14HLAG (5'-GTGATGGGCTGTTTAAAGTGTCACC-3') and RHG4 (5'GGAAGGAATGCAGTTCAGCATGA-3') (Hviid et al. 1999).

The PCR cycling conditions were as reported previously (Al Omar et al., 2015). The PCR products were analyzed according to the fragment sizes $(210 / 224 \mathrm{bp})$ by the presence or absence of a specific band in a 3\% agarose gel stained with ethidium bromide 
and visualized on an UV transilluminator using a gel documentation system (BioRad Gel225 Doc ${ }^{\mathrm{TM}} \mathrm{XR}+$, Hercules, CA, USA) (Figure 1).

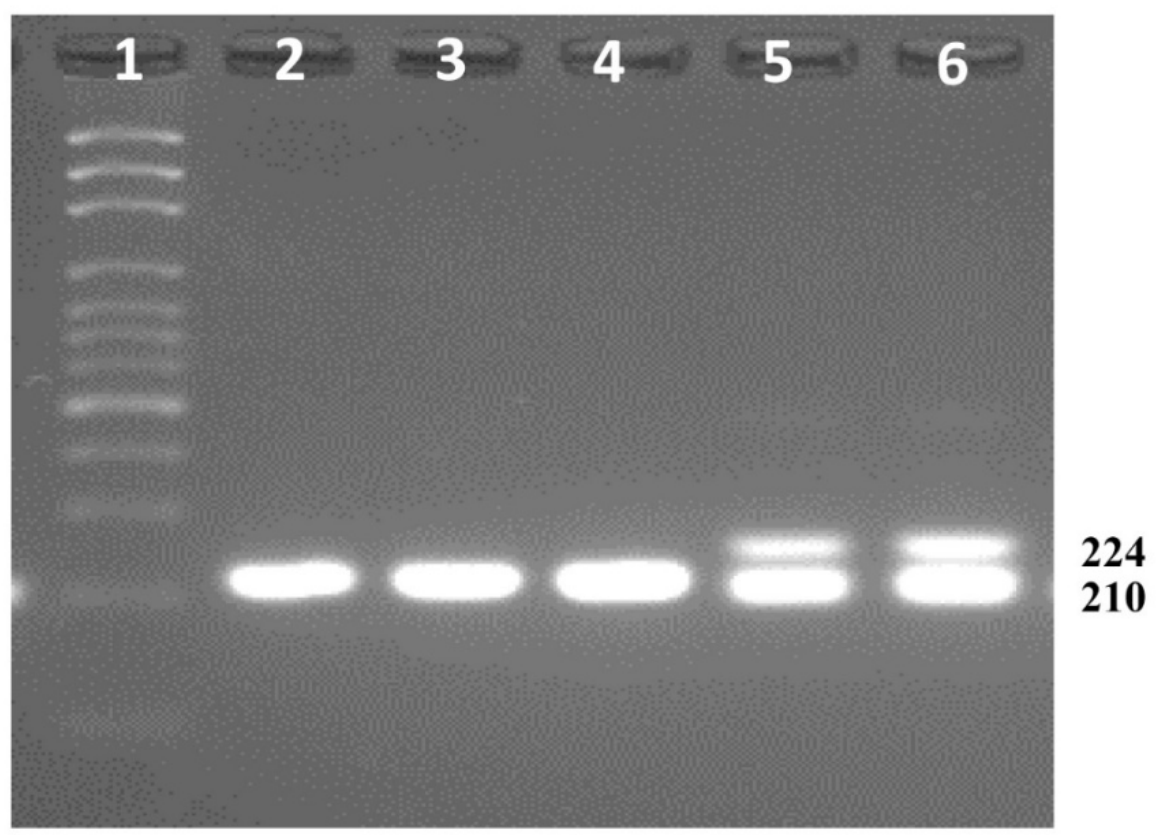

Figure 1. Photograph of the gel electrophoresis showing the detection of HLA-G 14-bp polymorphism among women with breast cancer4. Lane 1 is the 100-bp DNA ladder, Lanes 2 to 4 are homozygous $H L A-G-14-b p /-14-$ bp; lanes 5 and 6 are $H L A-G$ heterozygous.

\section{Statistical analysis}

Observed frequencies of insertion/deletion polymorphisms in $H L A-G$ alleles were determined by direct counting. Comparisons of allelic, genotypic, and haplotype frequencies between case and control groups were performed with the two-tailed Fisher's exact test using SigmaPlot software version 11.0 Build 11.0.0.77 (Systat Software, Inc., San Jose, CA, USA). The strength of association was estimated by calculating the odds ratio (OR) and its $95 \%$ confidence intervals (95\% CI). Statistical significance level was set at $5 \%$.

\section{RESULTS}

The frequencies of the $H L A-G$ 14-bp indel polymorphism in exon 8 at the 3 'UTR region and genotypes were compared between the patient and control groups, as shown in Table 2. Statistical analysis revealed a significant increase in the HLA-G 14-bp del in patients with $\mathrm{BC}(78 \%)$ compared to that in controls $(49 \%)(\mathrm{OR}=3.75 ; 95 \% \mathrm{CI}=2.08$ 6.76; $\mathrm{P}<0.001)$. Genotype frequency analysis showed that HLA-G 14-bp del/del was significantly more frequent in patients with BC (57\%) compared to healthy women (57\% 
versus $21 \%)(\mathrm{OR}=4.96 ; 95 \% \mathrm{CI}=2.17-11.34$ and $\mathrm{P}<0.001)$. It is worth noting that the homozygous genotype 14-bp ins/ins is missing among all studied patients.

The heterozygous genotype appeared more frequently among healthy women than in patients (56 vs. $43 \%$ ), but the difference was not significant.

Table 2. Distribution of the 14-bp insertion/deletion allele and genotype frequencies in breast cancer patients and control women in Saudi Arabia.

\begin{tabular}{|c|c|c|c|c|c|}
\hline Genotype & $\begin{array}{l}\text { BC } \\
\text { N (frequency) }\end{array}$ & \begin{tabular}{l|l} 
Control \\
N (frequency) \\
\end{tabular} & Odds ratio & Confidence interval & $P$ value \\
\hline 14-bp del & $80(0.78)$ & $61(0.49)$ & 3.75 & $2.08-6.76$ & 0.000008 \\
\hline 14-bp ins & $22(0.22)$ & $63(0.51)$ & 0.266 & $0.14-047$ & \\
\hline delldel & $29(0.57)$ & $13(0.21)$ & 4.96 & $2.17-11.34$ & 0.000098 \\
\hline ins/ins & $0(0.0)$ & $14(0.23)$ & 0 & 0 -na & $<000001$ \\
\hline ins/del & $22(0.43)$ & $35(0.56)$ & 0.58 & $0.27-1.23$ & 0.18 \\
\hline
\end{tabular}

\section{DISCUSSION}

HLA-G is a non-classical class I molecule and is the predominant HLA molecule expressed at the maternal-fetal interface by cytotrophoblast cells that do not express HLA class I molecules, apart from HLA-C at low levels and HLA-G (Rouas-Freiss et al., 1997b; Carosella et al., 2008a). HLA-G induces immune tolerance during pregnancy by inhibiting the cytolytic activity of peripheral natural killer cells and inducing the differentiation of immune-suppressive Treg cells (Rouas-Freiss et al., 1997a; Carosella et al., 2008a; Curigliano et al., 2013). This immune tolerance function of HLA-G protects the fetus from recognition and destruction by maternal immune cells and autoimmune disease, as well as increases the success of organ transplantation (Carosella et al., 2008a; Carosella et al., 2008b; Carosella et al., 2015; Fan et al., 2017; Lazarte et al., 2018).

Many studies have shown that the HLA-G molecule is relatively highly expressed in various types of tumors such as those of primary solid (melanoma, head and neck, lung, urogenital, gastrointestinal, and BCs) and hematologic malignancies (acute leukemia, lymphomas) and metastases (Tuncel et al., 2013; Karagoz et al., 2014; Lin and Yan, 2015; Zhang et al., 2018). This strategy may be used by tumors to escape immune surveillance (Rouas-Freiss et al., 2005b). Other studies have shown that the expression of HLA-G is influenced by the 14-bp ins/del polymorphism in 3' UTR (Hviid et al., 2006). In this study, we examined the relationship between the HLA-G 14-bp ins/del polymorphism and BC in Saudi women. Our results revealed a highly significant association between the 14-bp del allele and the occurrence of $\mathrm{BC}\left(\mathrm{OR}=3.75\right.$ and $\left.\mathrm{P}=8 \times 10^{-6}\right)$. Women sharing the homozygous genotype delldel were 5-fold more likely to develop BC than non-homozygous for this allele $\left(\mathrm{P}=9.8 \times 10^{-5}\right)$. Notably, no women with $\mathrm{BC}$ were homozygous for the ins allele. This result suggests that the 14-bp ins allele and ins/ins genotype could have a protective effect against the occurrence of BC in the Saudi population. In contrast, the 14-bp del allele and del/del genotype may be high-risk alleles when they are carried by Saudi women. Our results confirm the important effect of the HLA-G 14-bp ins/del polymorphism on the occurrence of $\mathrm{BC}$ in the Saudi population and agree with those reported previously (Eskandari-Nasab et al., 2013) showing an increased frequency of the del allele and del/del genotype among BC women compared to the controls in a south-east Iranian population 
(236 patients and 203 healthy controls). In this study, women with the del/del genotype were 2-fold more likely to develop BC than those non-homozygous for this allele. In another study conducted in a Brazilian population (80 patients and 191 normal), an association was found between the ins/del genotype and BC occurrence (Ramos et al., 2014). Interestingly, the wild-type ins/ins genotype was absent among Saudi patients, suggesting that the ins allele has a highly protective effect. However, in other studies, no associations were found in a group of women from northern Tunisia (Zidi et al., 2016). This was also observed in a South Korean population (Jeong et al., 2014) and Azeri population located in northwestern Iran (Haghi et al., 2015). In the latter study, a significant positive association was found between the del allele and advanced stages of BC (stage I vs stages II and III). Notably, in these three different studies, while no significant associations were found, the frequency of the del allele was increased among patients. This discrepancy in findings among studies may be related to genetic differences between the different ethnic populations investigated. Different results have also been reported regarding the association between the level of expression of HLA-G molecule and BC. While the majority of these studies have reported increased levels of HLA-G in patients (Chen et al., 2010; EskandariNasab et al., 2013; Jeong et al., 2014; Ramos et al., 2014; Zidi et al., 2016), a few studies, however, did not find differences between patients and controls (Palmisano et al., 2002). A recent meta-analysis revealed that the HLA-G 14-bp ins/del polymorphism may contribute to BC susceptibility and overall cancer risk in Asian populations (Ge et al., 2014). They reported a significant association between the ins allele and the homozygous ins/ins genotype and reduced risk of $\mathrm{BC}$. In conclusion, we found a strong association between the mutant 14-bp deletion of the HLA-G in the $3^{\prime}$ UTR region and the occurrence of BC in a Saudi population. These results support the involvement of this non-classical HLA tolerogenic molecule in breast carcinogenesis. We propose to extend this study to a larger number of cases covering other regions in Saudi Arabia, with the aim to verify the possibility of considering this polymorphism as a prognostic marker for BC.

\section{ACKNOWLEDGMENTS}

This work was supported by King Saud University, Deanship of Scientific Research, College of Science Research Center.

\section{CONFLICTS OF INTEREST}

The authors declare no conflict of interest.

\section{REFERENCES}

Al Omar SY, Mansour L, Alkhuriji AF, Alwasel S, et al. (2015). Genetic association between the HLA-G 14-bp insertion/deletion polymorphism and the recurrent spontaneous abortions in Saudi Arabian women. Genet. Mol. Res. 14: 286-293.

Anderson BO, Lipscomb J, Murillo RH and Thomas DB (2015). Breast Cancer. In: Gelband H, Jha P, Sankaranarayanan R, Horton S (eds) Cancer: Disease Control Priorities, Third Edition (Volume 3). Washington (DC).

Carosella ED, Favier B, Rouas-Freiss N, Moreau P, et al. (2008a). Beyond the increasing complexity of the immunomodulatory HLA-G molecule. Blood 111: 4862-4870.

Carosella ED, Moreau P, LeMaoult J and Rouas-Freiss N (2008b). HLA-G: from biology to clinical benefits. Trends Immunol 29: 125-132. 
Carosella ED, Rouas-Freiss N, Paul P and Dausset J (1999). HLA-G: a tolerance molecule from the major histocompatibility complex. Immunol. Today 20: 60-62.

Carosella ED, Rouas-Freiss N, Tronik-Le Roux D, Moreau P, et al. (2015). HLA-G: An Immune Checkpoint Molecule. Adv. Immunol. 127: 33-144.

Chen HX, et al (2010). Upregulation of human leukocyte antigen-G expression and its clinical significance in ductal breast cancer. Hum. Immunol. 71: 892-898.

Curigliano G, Criscitiello C, Gelao L and Goldhirsch A (2013). Molecular Pathways: Human Leukocyte Antigen G (HLA-G). Clin. Cancer Res. 19: 5564-5571.

Dausset J and Carosella ED (1999). HLA-G: a new opening for HLA. Semin. Cancer Biol. 9: 1.

de Almeida BS, Muniz YCN, Prompt AH, Castelli EC, et al. (2018). Genetic association between HLA-G 14-bp polymorphism and diseases: A systematic review and meta-analysis. Hum. Immunol. 79: 724-735.

Dias FC, Castelli EC, Collares CVA, Moreau P, et al. (2015). The Role of HLA-G Molecule and HLA-G Gene Polymorphisms in Tumors, Viral Hepatitis, and Parasitic Diseases. Front. Immunol. 6: 9.

Donadi EA, Castelli EC, Arnaiz-Villena A, Roger M, et al. (2011). Implications of the polymorphism of HLA-G on its function, regulation, evolution and disease association. Cell. Mol. Life Sci. 68: 369-395.

Eskandari-Nasab E, Hashemi M, Hasani SS, Omrani M, et al. (2013). Association between HLA-G 3'UTR 14-bp ins/del polymorphism and susceptibility to breast cancer. Cancer Biomark. 13: 253-259.

Fan W, Huang Z, Li S and Xiao Z (2017). The HLA-G 14-bp polymorphism and recurrent implantation failure: a metaanalysis. J. Assist. Reprod. Genet. 34: 1559-1565.

Galaviz-Hernandez C, Sosa-Macias M, Teran E, Garcia-Ortiz JE, et al. (2019). Paternal Determinants in Preeclampsia. Front. Physiol. 9.

Garcia A, et al. (2013). Association of HLA-G 3'UTR polymorphisms with response to malaria infection: a first insight. Infect. Genet. Evol. 16: 263-269.

Ge Y-Z, et al. (2014). Association between human leukocyte antigen-G 14-bp insertion/deletion polymorphism and cancer risk: A meta-analysis and systematic review. Hum. Immunol. 75: 827-832.

Geraghty DE, Koller BH and Orr HT (1987). A human major histocompatibility complex class I gene that encodes a protein with a shortened cytoplasmic segment. Proc. Natl. Acad. Sci. USA 84: 9145-9149.

Gibbons A, Groarke A and Sweeney K (2016). Predicting general and cancer-related distress in women with newly diagnosed breast cancer. BMC Cancer. 16: 935.

Gobin SJ and van den Elsen PJ (1999). The regulation of HLA class I expression: is HLA-G the odd one out? Semin. Cancer Biol. 9: 55-59.

Haghi M, Hosseinpour Feizi MA, Sadeghizadeh M and Lotfi AS (2015). 14-bp Insertion/Deletion Polymorphism of the HLA-G gene in Breast Cancer among Women from North Western Iran. Asian Pac. J. Cancer Prev. 16: 61556158.

Hortobagyi GN, et al. (2005). The global breast cancer burden: variations in epidemiology and survival. Clin. Breast Cancer. 6: 391-401.

Hviid TV, Rizzo R, Melchiorri L, Stignani M, et al. (2006). Polymorphism in the 5' upstream regulatory and 3 untranslated regions of the HLA-G gene in relation to soluble HLA-G and IL-10 expression. Hum. Immunol. 67: 53-62.

Hviid TV, Sorensen S and Morling N (1999). Polymorphism in the regulatory region located more than 1.1 kilobases $5^{\prime}$ to the start site of transcription, the promoter region, and exon 1 of the HLA-G gene. Hum. Immunol. 60: 12371244.

Jeong S, Park S, Park BW, Park Y, et al. (2014). Human leukocyte antigen-G (HLA-G) polymorphism and expression in breast cancer patients. PLoS One 9: e98284.

Jun K and Katsumi M (2009). HLA-G Molecule. Curr. Pharm. Des. 15: 3318-3324.

Karagoz B, et al. (2014). HLA-G in testicular germ cell tumors. Oncol. Res. Treat. 37: 245-248.

Kim SK, Chung JH, Jeon JW, Park JJ, et al. (2013). Association between HLA-G 14-bp insertion/deletion polymorphism and hepatocellular carcinoma in Korean patients with chronic hepatitis B viral infection. Hepatogastroenterology 60: 796-798

Koller BH, Geraghty DE, DeMars R, Duvick L, et al. (1989). Chromosomal organization of the human major histocompatibility complex class I gene family. J. Exp. Med. 169: 469-480.

Kovats S, Main EK, Librach C, Stubblebine M, et al. (1990). A class I antigen, HLA-G, expressed in human trophoblasts. Science 248: 220-223.

Lazarte J, Adamson MB, Tumiati LC and Delgado DH (2018). 10-Year Experience with HLA-G in Heart Transplantation. Hum. Immunol. 79: 587-593.

Lin A and Yan W-H (2015). Human Leukocyte Antigen-G (HLA-G) Expression in Cancers: Roles in Immune Evasion, Metastasis and Target for Therapy. Mol. Med. 21: 782-791.

Lin A and Yan WH (2018). Heterogeneity of HLA-G Expression in Cancers: Facing the Challenges. Front. Immunol. 9: 2164.

Menter T and Tzankov A (2018). Mechanisms of Immune Evasion and Immune Modulation by Lymphoma Cells. Front. Oncol. 8: 54.

Genetics and Molecular Research 18 (2): gmr18263 
Palmisano GL, Pistillo MP, Fardin P, Capanni P, et al. (2002). Analysis of HLA-G expression in breast cancer tissues. Hum. Immunol. 63: 969-976.

Ramos CS, Gonçalves AS, Marinho LC, Gomes Avelino MA, et al. (2014). Analysis of HLA-G gene polymorphism and protein expression in invasive breast ductal carcinoma. Hum. Immunol. 75: 667-672.

Rebmann V, LeMaoult J, Rouas-Freiss N, Carosella ED, et al. (2007). Quantification and identification of soluble HLA$\mathrm{G}$ isoforms. Tissue Antigens. 69 Suppl 1: 143-149.

Rolfsen GB, Castelli EC, Donadi EA, Duarte RA, et al. (2014). HLA-G polymorphism and breast cancer. Int. J. Immunogenet. 41: 143-148.

Rouas-Freiss N, Gonçalves RM-B, Menier C, Dausset J, et al. (1997a). Direct evidence to support the role of HLA-G in protecting the fetus from maternal uterine natural killer cytolysis. Proc. Natl. Acad. Sci. USA. 94: 11520-11525.

Rouas-Freiss N, Marchal RE, Kirszenbaum M, Dausset J, et al. (1997b). The alpha1 domain of HLA-G1 and HLA-G2 inhibits cytotoxicity induced by natural killer cells: is HLA-G the public ligand for natural killer cell inhibitory receptors? Proc. Natl. Acad. Sci. USA. 94: 5249-5254.

Rouas-Freiss N, Moreau P, Ferrone S and Carosella ED (2005a). HLA-G proteins in cancer: do they provide tumor cells with an escape mechanism? Cancer Res. 65: 10139-10144.

Rouas-Freiss N, Moreau P, Ferrone S and Carosella ED (2005b). HLA-G Proteins in Cancer: Do They Provide Tumor Cells with an Escape Mechanism? Cancer Res. 65: 10139-10144.

Rutten MJ, Dijk F, Savci-Heijink CD, Buist MR, et al. (2014). HLA-G expression is an independent predictor for improved survival in high grade ovarian carcinomas. J. Immunol. Res. 2014: 274584.

Sabbagh A, Sonon P, Sadissou I, Mendes-Junior CT, et al. (2018). The role of HLA-G in parasitic diseases. Hla. 91: 255-270.

Torre LA, Bray F, Siegel RL, Ferlay J, et al. (2015). Global cancer statistics, 2012. CA. Cancer. J. Clin. 65: 87-108.

Tuncel T, Karagoz B, Haholu A, Ozgun A, et al. (2013). Immunoregulatory function of HLA-G in gastric cancer. Asian Pac. J. Cancer Prev. 14: 7681-7684.

Vargas RG, Sarturi PR, Mattar SB, Bompeixe EP, et al. (2011). Association of HLA-G alleles and 3' UTR 14 bp haplotypes with recurrent miscarriage in Brazilian couples. Hum. Immunol. 72: 479-485.

Zambra FM, Biolchi V, de Cerqueira CC, Brum IS, et al. (2016). Immunogenetics of prostate cancer and benign hyperplasia--the potential use of an HLA-G variant as a tag SNP for prostate cancer risk. HLA. 87: 79-88.

Zhang S and Tao Wang H (2014). Association between HLA-G 14-bp insertion/deletion polymorphism and cancer risk: a meta-analysis. J. Buon. 19: 567-572.

Zhang Y, Yu S, Han Y, Wang Y, et al. (2018). Human leukocyte antigen-G expression and polymorphisms promote cancer development and guide cancer diagnosis/treatment. Oncol. Lett. 15: 699-709.

Zidi I and Ben Amor N (2011). HLA-G regulators in cancer medicine: an outline of key requirements. Tumour. Biol. 32 : 1071-1086.

Zidi I, Dziri O, Zidi N, Sebai R, et al. (2016). Association of HLA-G +3142 C >G polymorphism and breast cancer in Tunisian population. Immunol. Res. 64: 961-968. 